\title{
EDUCAÇÃO E ALFABETIZAÇÃO: contribuições da abordagem psicogenética para a pesquisa
}

\section{GIOVANA CRISTINA ZEN}

Universidade Federal da Bahia (UFBA). Professora da Faculdade de Educação. Pesquisadora do Grupo de Estudos e Pesquisas em Educação, Didática e Ludicidade (GEPEL) e do Grupo de Pesquisa Formação em Exercício de Professores (FEP). Programa de PósGraduação em Educação da FACED/UFBA. E-mail: giovanacristinazen@gmail.com. ORCID: 0000-0001-6405-9843.

\section{MARÍA CLAUDIA MOLINARI}

Universidad Nacional de La Plata (Argentina). Profesora en Ciencias de la Educación, Facultad de Humanidades y Ciencias de la Educación, Universidad Nacional de La Plata, República Argentina. Magíster en Ciencias con Especialidad en Investigaciones Educativas. DIE-CINVESTAV - México. E-mail: cmolinari@fahce.unlp.edu.ar ORCID: 0000-0002-5129-8500. 


\title{
EDUCAÇÃO E ALFABETIZAÇÃO: contribuições da abordagem psicogenética para a pesquisa
}

Esse Dossiê se inscreve em um conjunto de ações articuladas entre diversas Universidades da América Latina, em prol do fortalecimento da discussão sobre a alfabetização entendida como o ingresso nas culturas do escrito. Os trabalhos aqui apresentados tomam como referência as contribuições das investigações psicolinguísticas no âmbito da abordagem psicogenética propostas inicialmente por Emilia Ferreiro, responsável por inaugurar um novo campo teórico a partir de uma perspectiva de investigação original, tanto pela sua proposta metodológica como pelos resultados que dela surgiram.

Palavras-chave: Educação. Alfabetização de Crianças, Jovens e Adultos. Abordagem Psicogenética.

\section{EDUCATION AND LITERACY: contributions of the psychogenetic approach to research}

This dossier is part of a set of actions articulated by several universities in Latin America, in order to strengthen the discussion on literacy, understood as the entrance on the cultures of writing. The works presented here take the contributions of psycholinguistic investigations within the scope of the psychogenetic approach initially proposed by Emilia Ferreiro as a reference, responsible for opening a new theoretical field from an original research perspective, both for its methodological proposal and for the results that have emerged from it.

Keywords: Education. Literacy of Children, Youth and Adults. Psychogenetic Approach.

\section{EDUCACIÓN Y ALFABETIZACIÓN: contribuciones del enfoque psicogenético para a la investigación}

EEste dossier forma parte de un conjunto de acciones articuladas entre varias universidades de América Latina, a favor de fortalecer la discusión sobre la alfabetización entendida como el ingreso en las culturas de lo escrito. Los trabajos aquí presentados toman como referencia los aportes de las investigaciones psicolingüísticas en el ámbito del abordaje psicogenético inicialmente propuesto por Emilia Ferreiro, responsable de abrir un nuevo campo teórico desde una perspectiva de investigación original, tanto por su propuesta metodológica como por los resultados que emergieron.

Palabras clave: Educación. Alfabetización de Niños, Jóvenes y Adultos. Enfoque Psicogenético.

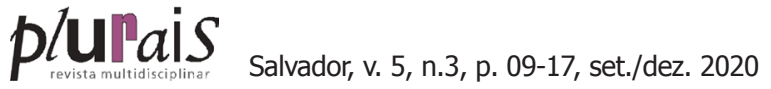

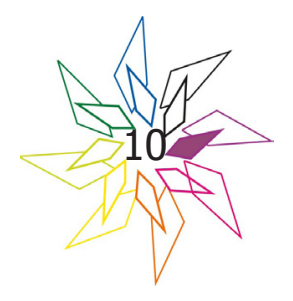




\title{
EDUCAÇÃO E ALFABETIZAÇÃO: contribuições da abordagem psicogenética para a pesquisa
}

Os estudos de Ferreiro provocaram significativas rupturas epistemológicas no campo das pesquisas psicolinguísticas sobre a aprendizagem da língua escrita e colocaram em questão pressupostos da psicologia cognitiva. Uma delas refere-se à própria compreensão sobre a escrita, entendida pelos pesquisadores da abordagem cognitivista como um código de transcrição direta e linear entre as unidades da linguagem oral e as unidades do escrito. No sentido oposto, a concepção de escrita que orienta as pesquisas psicogenéticas considera a escrita como "un instrumento conceptual: un sistema de representación que organiza un modo de objetivar el lenguaje" (Zamudio, 2020, p. 127), produto de um longo processo de construção histórico-cultural. Nas palavras de Ferreiro,

\begin{abstract}
Para compreender este processo de apropriação, foi necessário renunciar à visão da escrita como técnica (ou "código de transcrição", se preferir) e despojar-se de toda ideia instrumental. Foi necessário tornar complexa nossa própria concepção da escrita, para compreender o processo de alfabetização, para entender o que as crianças estavam nos dizendo. Da mesma forma que a história da escrita através dos povos e dos séculos não é redutível a um percurso linear guiado pela eficiência e simplicidade da transcrição dos enunciados orais, os processos de apropriação da escrita pelas crianças também não podem se caracterizar como uma progressão do simples (fonemas ou sílabas) ao complexo (orações ou textos), do concreto (o desenho) ao abstrato (as letras). A escrita como objeto de conhecimento. Talvez esta tenha sido a contribuição central do nosso trabalho de pesquisa. (2013, p. 30)
\end{abstract}

Nesta perspectiva teórica, a escrita é considerada como um objeto cultural construído historicamente e sua apropriação pressupõe um processo de reconstrução conceitual. Assim, quem aprende a ler e a escrever é considerado como um sujeito intelectualmente ativo, que enfrenta o desafio de compreender o funcionamento do sistema de escrita.

Temos que auxiliar essas crianças em seu caminho para a alfabetização, mas levando em conta sua inteligência e não as tratando como ignorantes. Elas colocam questões legitimas - algumas delas de grande relevância epistemológica - ao pensar a escrita; a mesma escrita reduzida, banalizada e deformada pela tradição escolar, que converte didaticamente um objeto 
cultural complexo em um instrumento de codificação rudimentar. FERREIRO (2013, p. 33)

A compreensão sobre o sujeito que aprende, representa outra importante ruptura epistemológica nas investigações construtivistas psicogenéticas. Desde as primeiras indagações realizadas por Ferreiro e Teberosky (1979), as opções metodológicas desafiavam os sujeitos a ler e escrever palavras ou frases que ainda não haviam sido ensinadas. Isso permitiu compreender as ideias originais inerentes ao processo de «criação» dos escritos e aos processos de interpretação do escrito em tarefas com complexidades diversas. Segundo Ferreiro, "este quiebre epistemológico fue decisivo porque nos permitió asistir a la creación de escrituras, según la idea de escritura que tenían los niños" (Ferreiro, 2019b, p.20).

O valor dos resultados não previstos e a compreensão das suas respostas originais, num diálogo clínico-crítico com os sujeitos, marca uma ruptura com o paradigma clássico, no qual se espera a confirmação de hipóteses previamente formuladas pelo pesquisador. Nas pesquisas no campo da psicologia cognitiva, as respostas "desviantes" ou "erradas" encontradas na coleta de dados são identificadas como incorretas ou são classificadas de acordo com sua proximidade em relação a uma determinada habilidade. Como explica Ferreiro, na abordagem psicogenética,

\footnotetext{
[...] la reflexión metalingüística a la que invitamos a los chicos no los conducirá a ninguna «evidencia lógica» (como en el caso de las célebres situaciones de indagación de Piaget sobre la conservación del número, de la cantidad de materia, del peso, etc.). Por el contrario, la reflexión sobre el lenguaje los conducirá muy a menudo a constatar disparidades, usos aparentemente contradictorios, unidades difíciles de caracterizar y otras singularidades. (2019a, p.10)
}

Tal como explica a autora, "son estudios sobre las posibilidades de reflexión de los niños pero que nos obligan a ver con nuevos ojos fenómenos ineludibles de la escritura y de la oralidad. La palabra de los que no están autorizados a tomar la palabra nos puede ayudar a reflexionar. Tratemos de escuchar." (FERREIRO, 2019a, p.11-12).

A vasta produção científica relacionada ao construtivismo psicogenético tem contribuído com avanços significativos ao investigar os processos de reconstrução de sistemas de escrita de base alfabética, os problemas ortográficos que os aprendizes enfrentam e resolvem segundo características das diferentes línguas, os numerosos estudos sobre pontuação, a leitura e escrita em diversos

\section{plurais}


meios e instrumentos digitais, as continuidades e especificidades dos processos de alfabetização de crianças, jovens e adultos, etc.

Além disso, vale destacar que a reflexão sobre as criações intelectuais dos sujeitos tem impactado o campo específico da didática da leitura e da escrita. Em diversos países da América Latina, as numerosas investigações e experiências sistematizadas por pesquisadores e educadores têm ajudado a fundamentar e consolidar decisões didáticas em torno das práticas de ensino que assumem uma perspectiva construtivista e interacionista.

Nesta perspectiva, as análises das interações que se realizam em uma situação de ensino assumem uma dimensão complexa e não se reduzem à aplicação direta de conhecimentos produzidos em diversos campos. Ao considerar as contribuições da didática da matemática, Lerner (2002) esclarece que,

O saber didático é construído para resolver problemas próprios da comunicação do conhecimento, é o resultado do estudo sistemático das interações que se produzem entre o professor, os alunos e o objeto de ensino; é produto da análise das relações entre o ensino e a aprendizagem de cada conteúdo específico; é elaborado através da investigação rigorosa das situações didáticas. (2002, p. 105)

Nesse sentido, o processo de alfabetização deve se dar a partir de uma relação complexa dos alunos com as diversas culturas do escrito das quais nascerem herdeiras. Por este motivo, as diversas concepções de alfabetização não são destituídas de intenções políticas. Cada concepção é definida por uma perspectiva sobre quem são esses sujeitos, que lugar ocupam nesse processo de aquisição, de que forma podem (ou não) assumir como cidadãos o direito de serem ouvidos e compreendidos quando refletem sobre o que lhes ensinam. A alfabetização é, portanto, um campo de disputas teóricas em que se contrapõem bases epistemológicas e perspectivas políticas muito distintas.

Os trabalhos que apresentamos neste Dossiê Temático se inscrevem na perspectiva construtivista e tomam como referência o processo de alfabetização como processo de apropriação crítica das práticas sociais de leitura e escrita, um processo complexo de construção conceitual em que é indispensável compreender as interpretações de crianças, jovens e adultos. Os artigos resultam de pesquisas realizadas na Universidade de São Paulo e na Universidade Estadual de Campinas no

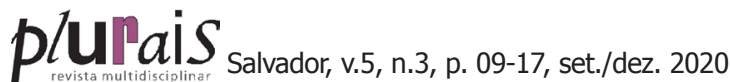


Brasil, na Universidade Nacional Autônoma do México, na Universidade de Buenos Aires e na Universidade Nacional de La Plata, na Argentina; além dos textos que foram submetidos no fluxo contínuo da Revista Plurais. Para o Dossiê Temático, temos seis textos.

O primeiro artigo, intitulado A utilidade do conhecimento do nome da letra para a aquisição do sistema de escrita, de Giulianny Russo Marinho e Mónica Alvarado, apresenta os resultados de uma investigação que pretendia compreender a relação entre a identificação de letras por seus respectivos nomes e a possibilidade de utilizá-las de maneira pertinente na escrita de contextos e no preenchimento de palavras, observando a influência exercida pela motivação fonológica das letras. Participaram da pesquisa 48 crianças pré-alfabéticas entre 5 e 6 anos, regularmente matriculadas em escolas públicas da região central de São Paulo/SP. Os resultados indicam que as possibilidades da criança usar e integrar informações para escrever e completar palavras não dependem do conhecimento do nome da letra, mas dos níveis de conceituação que têm sobre o funcionamento do sistema de escrita.

O segundo texto que compõe esse dossiê, intitulado Enfoques y debates en torno a los procesos de alfabetización en personas jóvenes y adultas: revisión actualizada, de autoria de Marcela Kurlat, propõe uma reflexão sobre os debates e abordagens em torno da alfabetização de jovens e adultos, resgatando o estado da arte que tem apoiado pesquisas de mestrado, doutorado e pós-doutorado no âmbito do Programa de Desarrollo Sociocultural y Educación Permanente, com sede no Instituto de Investigaciones en Ciencias de la Educación da Universidad de Buenos Aires. Essas investigações pretendem contribuir para a compreensão dos processos de apropriação do sistema de escrita por jovens e adultos, bem como as intervenções didáticas que promovem a sua construção, a partir de uma epistemologia construtivista. A autora apresenta algumas investigações oriundas de suas próprias indagações, assim como perspectivas em disputa que "dividem águas" ao sustentar políticas de alfabetização. A discussão apresentada ao longo do texto contribui para a tomada de decisões pedagógicas, didáticas e políticas no âmbito de programas de alfabetização para jovens e adultos.

Ainda nesta modalidade, Marina Kriscautzky Laxague e Adriana Areli Bravo Lozano propõem uma discussão no âmbito da alfabetização de jovens e adultos. No texto intitulado Alfabetización de adultos desde una perspectiva psicogenética apresentam resultados de uma pesquisa sobre as hipóteses que adultos não alfabetizados elaboram a respeito do sistema de escrita, suas

\section{plurais}

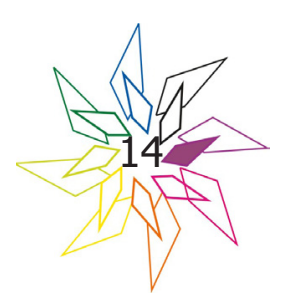


semelhanças e diferenças quanto ao processo estudado por Ferreiro e Teberosky (1979) com crianças. Além disso, também abordam as implicações acerca da alfabetização de adultos, sob uma perspectiva psicogenética. A partir da análise de atividades de leitura e escrita realizadas por idosos em momentos anteriores à compreensão alfabética do sistema escrita, as autoras concluíram que existem importantes semelhanças entre crianças e adultos no processo de construção do conhecimento sobre o sistema de escrita. Destacam ainda que o reconhecimento do processo de construção de conhecimento é imprescindível quando se pensa em alfabetizar respeitando as pessoas. Assinalam que esse respeito não se refere apenas aos interesses pessoais ou às histórias de vida, mas também (e principalmente) ao direito de jovens e adultos serem respeitados como pessoas que pensam e não como meros receptores de informação.

O quarto texto deste dossiê, intitulado Comentários diretos e indiretos na revisão textual utilizando ferramentas digitais, de Miruna Kayano Genoino e Marina Kriscautzky Laxague apresenta uma reflexão sobre a possibilidade de revisar, comentar e interpretar por escrito através de ferramentas digitais. A investigação foi realizada com crianças de 7 anos de idade que frequentavam o $2^{\circ}$ ano do Ensino Fundamental de uma escola particular de São Paulo/SP. As principais questões da pesquisa consistem em compreender qual conteúdo linguístico as crianças poderiam selecionar para comentar os textos quais estratégias de comunicação usariam com a ferramenta digital proposta e como seriam as trocas orais no processo de revisão dos textos. Os resultados provocam uma reflexão acerca dos diferentes espaços em que os alunos inscrevem comentários nos textos dos colegas e os impactos de diferentes tipos de comentários diretos e indiretos no texto. Por fim, destacam a importância das trocas orais entre os pares de autores e comentaristas para compreender os diferentes aprendizados que foram desenvolvidos na proposta didática.

A discussão sobre $A$ construção do conhecimento ortográfico no contexto das interações adulto-criança é o tema de investigação do quinto texto do dossiê. As autoras Elaine C. R. Gomes Vidal e Silvia M. Gasparian Colello apresentam os resultados de uma investigação sobre o papel da interação entre o adulto e criança na construção do conhecimento ortográfico. Para tanto, recuperam parte de um estudo de caso longitudinal em curso, realizado com alunos de uma escola privada em Santos/SP, em cinco etapas entre o $2^{\circ}$ e o $4^{\circ}$ ano do Ensino Fundamental. Valendo-se do referencial teórico dos estudos psicogenéticos e histórico-culturais, o estudo centrou-se na problematização sobre as formas de escrever. A partir das atividades propostas (ditado de palavras e reescrita de contos), a coleta de dados visou apreender a compreensão das estratégias infantis ou

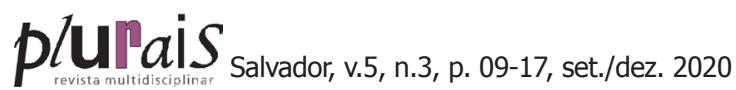


das reflexões empreendidas na busca de referências para a correção da escrita, chegando, assim, a quatro categorias: a escrita validada pela pauta sonora, a validação da escrita com base em alguém mais experiente, o apoio na imagem visual da palavra e, finalmente, a evocação da norma ortográfica. Embora essas categorias estejam sempre presentes nos diferentes estágios de escolaridade (e de conhecimento), a análise quanti-qualitativa dos dados evidenciou o predomínio de umas sobre as outras que, em movimentos ascendentes e descendentes, marcam um percurso de crescente autonomia e consciência metalinguística. Por fim, as autoras vislumbram algumas implicações pedagógicas que subsidiam a revisão de práticas pedagógicas.

As relações entre as práticas de leitura propostas por professoras e o impacto na formação dos alunos enquanto leitores fecha o conjunto de artigos que compõe este dossiê. No texto que leva o título Leitura e Leitores: o que dizem as crianças sobre a leitura feita na escola. Renata B. Siqueira Frauendorf, Heloísa Helena Dias Martins Proença e Guilherme do Val Toledo Prado apresentam os resultados de uma investigação realizada com crianças de 4 a 10 anos, pertencentes a escolas da rede pública e privada, em diferentes municípios brasileiros. A participação e escuta das crianças aconteceu por meio de rodas de conversas, mediadas por professoras-pesquisadoras, em que no mínimo cinco questões, previamente elaboradas, foram propostas para disparar a conversa e troca entre os alunos. Os autores destacam que a presença de situações de leitura realizadas pelo professor é identificada pelas crianças como parte da rotina escolar, entretanto esse movimento ainda tem sido insuficiente para formar alunos leitores e críticos. Apesar da intencionalidade e planejamento dos professores para este momento da rotina, os percursos de leitores, da maioria dos alunos participantes da pesquisa, estão sendo marcados mais por livros lidos do que experiências significativas de leitura literária.

Assim, este Dossiê Temático resulta de um esforço coletivo cujo propósito consiste em divulgar resultados de pesquisa e reflexões que podem inspirar outros investigadores do campo da alfabetização. Inserem-se, ainda, aqui, textos de pesquisadores/as do campo da Educação, que apresentam discussões teóricas relevantes, desenvolvidas em suas pesquisas.

Desejamos a você uma boa leitura!

\section{plurais}

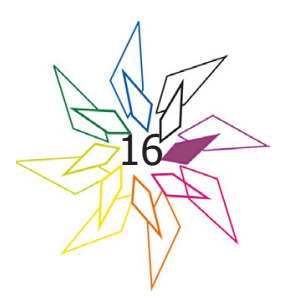




\section{REFERÊNCIAS}

BORZONE, A. M.; SIGNORINI, A. Del habla a la escritura. La conciencia linguística como una forma de transición natural. Lectura Y Vida, 9/2, p. 5-9, 1988.

FERREIRO, E. O ingresso na escrita e nas culturas do escrito. São Paulo, Cortez. 2013.

FERREIRO, E. [et al.] Reflexiones metalingüísticas de los niños sobre aspectos de la escritura del español. Rosario: Humanidades y Artes Ediciones - HyA ediciones, 2019a.

FERREIRO, E. Research perspectives in beginning literacy. Methodological and epistemic dichotomies / Prospectivas en investigación sobre alfabetización inicial. Dicotomías metodológicas y epistemológicas, Infancia y Aprendizaje / Journal for the Study of Education and Development, v. 42, n. 1, p. 01-36, 2019 b.

FERREIRO, E; TEBEROSKY, A. Los sistemas de escritura en el desarrollo del niño. México: Siglo XXI, 1979.

LERNER, Delia. Ler e Escrever na escola: o real, o possível e o necessário. Porto Alegre: ARTMED, 2002.

ZAMUDIO, C. Objetivación del lenguaje y conocimiento metalingüístico: transformaciones que posibilita la escritura. Lingüística Mexicana. Nueva Época, v. 2, n. 2, p. 99-131, 16 jun. 2020.

Recebido em: 10 de setembro de 2020 .

Inserido em: 15 de outubro de 2020.

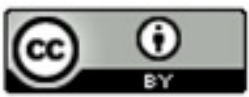

Esta obra está licenciada com uma Licença Creative Commons Atribuição 4.0 Internacional.

\section{Plulail $S_{\text {revista multidiscilinar }}$ Salvador, v.5, n.3, p. 09-17, set./dez. 2020}

